\title{
LA VERDAD SOBRE MACEDONIA
}

Los griegos y sus descendientes, agrupados en la Federación de Colectividades Helénicas de Chile, desean apoyar totalmente los esfuerzos del Gobierno Griego para manifestar a la comunidad internacional, que la usurpación histórica y étnica por parte de FYROM de Macedonia, de un Estado y civilización de la Antigüedad que se formó indudablemente como una región geográfica y que se extiende en los actuales territorios de cuatro países (Grecia cubre el 51 o 54\%, FYROM el 37 o 34\%, Bulgaria el 11\% y Albania el 1\%), además de violar los principios de buena vecindad. Desestabiliza la región de los Balcanes.

Para entender la problemática que se ha suscitado con FYROM (Former Yugoslave Republic of Macedonia), hay que recordar la historia: el reino de Macedonia - que es una palabra griega - fue un Estado de la Antigüedad, en el norte de la actual Grecia, formando parte de la herencia nacional e histórica de Grecia, que se consolidó en el siglo V a. C y alcanzó su plenitud, primero con Filipo II, y luego con su hijo Alejandro Magno. Además, los historiadores atribuyen a sus habitantes el carácter de griegos, que utilizaban el dialecto dórico, al igual de los habitantes de Epiro, Rodas y el Peloponeso, y lo sigue siendo hasta hoy, una de las más vastas regiones de Grecia. Macedonia, cuya capital Tesalónica es la segunda ciudad de Grecia.

La historia de los Balcanes es una historia de dolorosas guerras e invasiones; pero ni los romanos, ni godos, ni hunos, ni ávaros, lograron alterar en forma significativa a Macedonia. Entre los siglos VII y XIV, Macedonia fue sometida por los distintos imperios de turno, hasta quedar bajo la dominación otomana. Tras las dos Guerras de los Balcanes - 1912 y 1913 -, fue repartida entre Grecia (la mayor parte) y Serbia, constituyendo en esta última la provincia de Vardar Banovina.

Ya en tiempos actuales, en 1994, en un intento por seguir un avance territorial y buscando una salida al mar a través de Grecia, el Mariscal Tito de Yugoslavia cambió el nombre "Vardar Banovina" por el de "República de Macedonia" y lanzó desde allí sus ataques contra Grecia.

Tras la disolución de Yugoslavia en 1991, la Antigua República Yugoslava de Macedonia, declaró su independencia bajo el nombre "República de Macedonia", monopolizando así la noción de "Macedonia", 
que es más amplia y no puede monopolizarsee por ningún Estado en términos políticos, históricos y geográficos. Para evitar complicaciones al respecto, la ONU aceptó el nuevo Estado bajo el nombre provisorio - la Antigua República Yugoslava de Macedonia, provisoriamente "FYROM" - y hasta que los dos Estados lleguen a un acuerdo común por el nombre del nuevo Estado, respetando de esta manera las sensibilidades históricas de todas las partes involucradas.

Han transcurrido casi 17 años desde que el nombre provisorio fuera establecido y los griegos del mundo exigimos que se cumpla el compromiso para la búsqueda de un nombre de común acuerdo. El problema es que FYROM, insistiendo en la adopción de un nombre que usurpa la verdad histórica y cultural de Macedonia, esconde reivindicaciones territoriales e irredentistas frente a Grecia.

Llamamos a las comunidades helénicas de Chile y a todos los organismos culturales, políticos, educacionales, sociales y comunidad en general, a hacerse partícipes de esta legítima demanda del pueblo de Grecia.

Elena Burnas Vásquez

Secretaria
Miguel Politis Jaramís

Presidente

Coquimbo, Chile, 3 de abril de 